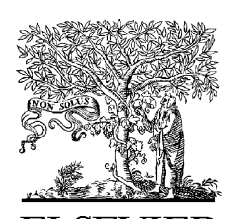

PRIMARY CARE

RESPIRATORY

JOURNAL

ELSEVIER

http:// intl.elsevierhealth.com/journals/pcrj/

\title{
EDITORIAL
}

\section{Assessing the severity of COPD}

In the UK, modern interest in what is now called chronic obstructive pulmonary disease (COPD) began following the large numbers of deaths seen as a result of the smog and pollution occurring in London during the 1950s [1]. Around this time spirometry was becoming available and it was observed that airflow obstruction was a key factor in determining disability and mortality [2]. These studies, and confusion about the best terminology to use in epidemiological studies, led to the 1958 CIBA symposium which suggested definitions of chronic bronchitis, emphysema, and variable and fixed airflow obstruction [3]. The introduction of a physiological consept of dirilow limitation as a diagnbst c terin was new, and for a ons aire (cing was known as chonid obstruc ive ai ways disease (1)(10.10) as d retiection of this airway-dominated definition. Consequently, it also seemed logical to base the classification of disease severity on the degree of airflow obstruction.

The term 'COPD' was coined in the early 1960s, and has been preferred to the term 'COAD' since the 1990s because it encapsulates the fact that the condition not only affects the airways but also affects the lung parenchyma and the pulmonary circulation. More recently, it has become clear that COPD also has effects outside the lung, most notably on skeletal muscle. One of the consequences of this broader view of the disease has been a reassessment of how to assess disease severity.

It is important to consider what is meant by the term 'severity' in relation to COPD, and why it is useful to assess it. For COPD, the 'severity of illness' is different to the 'severity of disease'. Essentially, 'severity of illness' concerns the level of suffering and disability experienced by the patient, whereas 'severity of disease' concerns the risk of death, suffering and disability [4]. Assessing the severity of disease is important, since it allows interventions to be used at appropriate stages of the disease, it allows a more accurate prognosis to be given, and it allows accurate characterization of patients and populations in clinical trials.

Assessment of disease severity in COPD is complicated by the multi-system nature of the disease and the heterogeneity ofliots clinical presentation: it mist Sonbine markers of the effert of the disense on the lungs with other knlowe prognostic factors. The pre- and postbronchodilat or (iterl expiratory volume in one se -olic Uitev, can be used to assess the severity of lairflow obstruction but other factors such as the patient's exercise capacity, the frequency of exacerbations, the degree of breathlessness (using the MRC scale), the transfer factor $\left(T_{L} C O\right)$, body mass index (BMI), partial pressure of oxygen in arterial blood $\left(\mathrm{PaO}_{2}\right)$ and the presence of cor pulmonale must be considered to give a better picture of the severity of disease [5].

Many patients with COPD lose weight and there has been considerable interest in the consequences of this, particularly as to whether it is an independent predictor of outcome or whether it is simply a feature of end-stage COPD [6-8]. Body mass can be divided into fat mass and fat-free mass (FFM) and it is the loss of FFM, which includes skeletal muscle, which appears to be most relevant to prognosis [9]. Loss of FFM is an independent predictor of outcome in patients with mild to moderate COPD and is thus not just a consequence of advanced disease [10].

Current national and international guidelines acknowledge the need to consider factors such 
as breathlessness and nutritional status when assessing disease severity, but recognize the difficulty of assessing all of these factors in practice. The NICE guideline classifies the severity of airflow obstruction into mild, moderate and severe on the basis of the reduction in $\mathrm{FEV}_{1}$ [5]. The guideline points out that spirometry alone may underestimate the impact of the disease in some patients and overestimate it in others. It also recommends assessment of other prognostic factors, but in the absence of an easily applied multi-dimensional tool it does not attempt to define disease severity.

The GOLD initiative uses FEV 1 to categorize the severity of COPD in a scheme which it describes as "a pragmatic approach aimed at practical implementation" which "should only be regarded as an educational tool, and a very general indication of the approach to management" [11]. In addition to the three categories in the NICE guideline, GOLD includes a Stage 1 category of mild COPD which is defined as a reduced $\mathrm{FEV}_{1}$ /forced vital capacity (FVC) ratio with $\mathrm{FEV}_{1} \geq 80 \%$ predicted. Stages 2,3 \& 4 are equivalent to the NICE stages 'mild', 'moderate' and 'severe', but in GOLD are named 'moderate', 'severe' and 'very severe'. GOLD also includes a Stage 0 "at risk group" with chronic symptoms but normal lu 19 function.

A multidimensional in dex wition incorporates

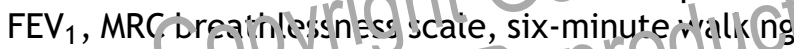
distance and BMi has recently been polished [12]. A similar index combining $\mathrm{FEV}_{1}, \mathrm{MRC}$ breathlessness scale and BMI has been developed in the UK [13]. Such indices perform better than severity assessments based purely on $\mathrm{FEV}_{1}$ as judged by prediction of survival and correlation with healthrelated quality of life [14].

The study by Steuten et al. [15] in this issue of the Primary Care Respiratory Journal further emphasizes the importance of a multidimensional assessment of COPD severity. The authors examined the frequency with which patients in the community had a high MRC breathlessness score, an abnormally high or low $\mathrm{BMI}$, or a low FFM index, when stratified by GOLD stages. They found that a significant proportion of patients with GOLD stage 1 and 2 disease experience significant dyspnoea, are obese or underweight, or have a low FFM index.

Assessing the severity of disease using known prognostic factors combined in these scoring systems is undoubtedly a step forward and is particularly useful for characterizing populations and predicting outcomes. However, it is also important to remember that the 'severity of illness' matters just as much to patients as the 'severity of disease', and that management should be focused around patients' needs, as well as being targeted according to disease severity.

\section{References}

[1] Samet JM. Definitions and methodology in COPD research. In: Hensley MJ, Saunders NA, editors. Clinical Epidemiology of Chronic Obstructive Pulmonary Disease. New York: Marcel Dekker; 1989. p. 1-22.

[2] Miller MR. Chronic obstructive pulmonary disease and '150 years of blowing'. Hosp Med 1998;59(9):719-22.

[3] CIBA foundation guest symposium. Terminology, definitions and classification of chronic obstructive pulmonary emphysema and related conditions. Thorax 1959;14:286-99.

[4] Almeida RT, Carlsson P. Severity of a case for outcome assessment in health care-definitions and classification of instruments. Health Policy 1996;37(1):35-52.

[5] National Institute for Clinical Excellence (NICE). Chronic obstructive pulmonary disease. National clinical guideline for management of chronic obstructive pulmonary disease in adults in primary and secondary care. Thorax 2004;59(Suppl 1):1-232.

[6] Gray-Donald K, Gibbons L, Sian,ro SH, Nacklem PT, Martin JG N/ ritch siatus and mortality in chronic o) tructive putmonary disease. Am J Respir Crit Care Med is96;153(3): :61-

[7] Schols $\wedge$, $S$ ans $\operatorname{rl}$, voiovics L, Wouters EF. Weight loss is - reversible factor in the prognosis of chronic obstructive pulmonary disease. Am J Respir Crit Care Med 1998;157(6 Pt 1):1791-7.

[8] Landbo C, Prescott E, Lange P, Vestbo J, Almdal TP. Prognostic value of nutritional status in chronic obstructive pulmonary disease. Am J Respir Crit Care Med 1999;160(6):1856-61.

[9] Schols AM, Broekhuizen R, Weling-Scheepers CA, Wouters EF. Body composition and mortality in chronic obstructive pulmonary disease. Am J Clin Nutr 2005;82(1): 53-9.

[10] Vestbo J, Prescott E, Almdal T, Dahl M, Nordestgaard BG, Andersen T, et al. Body Mass, Fat Free Body Mass and Prognosis in COPD Patients from a Random Population Sample. Am J Respir Crit Care Med 2005.

[11] Pauwels RA, Buist AS, Calverley PM, Jenkins CR, Hurd SS. Global strategy for the diagnosis, management, and prevention of chronic obstructive pulmonary disease, NHLBI/WHO Global Initiative for Chronic Obstructive Lung Disease (GOLD) Workshop summary. Am J Respir Crit Care Med 2001;163(5):1256-76.

[12] Celli BR, Cote CG, Marin JM, Casanova C, Montes de Oca M, Mendez RA, et al. The body-mass index, airflow obstruction, dyspnea, and exercise capacity index in chronic obstructive pulmonary disease. N Engl J Med 2004;350(10): 1005-12.

[13] Lawrence AD, Keaney NP. Classification of COPD patients using airflow limitation significantly underestimates the clinical impact of disease. Am J Respir Crit Care Med 2002;165(8):A442.

[14] van Nooten FE, Van Wetering CR, Schols AM, Rutten-van Molken M. BODE is better associated with quality of life 
(QoL) than GOLD: data from the INTERCOM trial. Eur Respir J 2005;26(Suppl 49):218S.

[15] Steuten LMG, Creutzberg EC, Vrijhoef HJ, Wouters E. COPD as a multicomponent disease: inventory of dyspnoea, underweight, obesity and fat free mass depletion in primary care. Prim Care Resp J 2006;15(2): 84-91.
David M.G. Halpin* Royal Devon \& Exeter Hospital, Exeter, EX2 5DW, UK * Tel.: +44 (0)1392 402133; fax: +44 (0)1392 402828 .

E-mail address: D.M.G.Halpin@ex.ac.uk

6 October 2005

Available online at www.sciencedirect.com SCIENCE

\section{Available online at http://www.thepcrj.com}

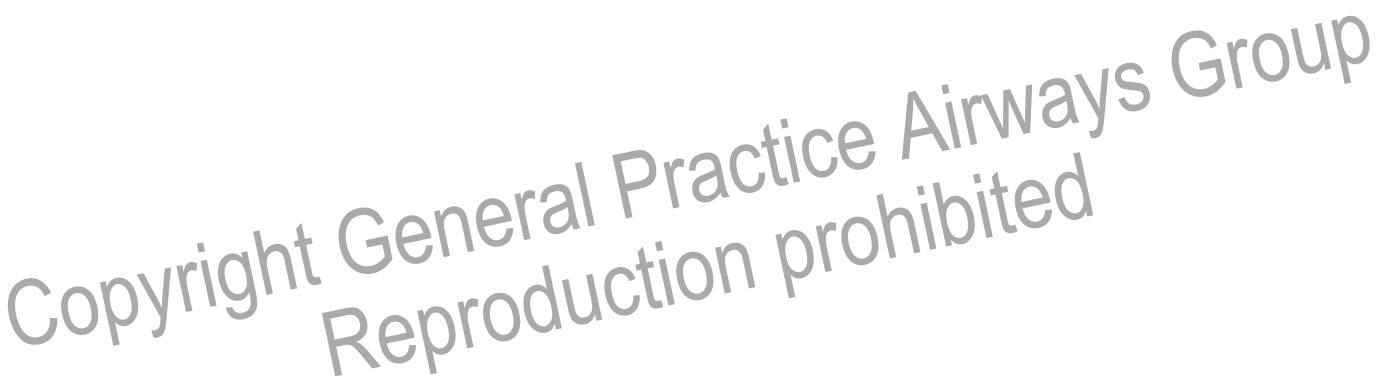

